\title{
Resistivity Enhancement of Sr-Hexaferrite Using Rare Earth Dopant to Minimize Energy Losses
}

\author{
Nahall Niazi ${ }^{\mathrm{a}}$, Omer Farooq ${ }^{\mathrm{b}}$, Fatima-tuz-Zahra ${ }^{\mathrm{c}}$ \\ and Muhammad Anis-ur-Rehman ${ }^{\mathrm{d},}$
}

\author{
Applied Thermal Physics Laboratory (ATPL), Department of Physics, \\ COMSATS Institute of Information Technology, Islamabad 44000, Pakistan \\ anahall2524@gmail.com, bomerfarooq.ciit@gmail.com, \\ cfatima.zahra@comsats.edu.pk, ${ }^{d}$ marehman@comsats.edu.pk
}

\begin{abstract}
Keywords: Strontium Hexaferrite, AC Conductivity, Dielectric Constant, Dielectric Loss.
\end{abstract}
\begin{abstract}
Strontium hexaferrite is a material of choice due its various magnetic applications. Energy losses are a prominent issue in these magnetic materials. To lower these energy losses, we need to improve the resistivity by reducing eddy current losses. In this work nanoparticles of Gadolinium (Gd) doped Sr-hexaferrite $\left(\mathrm{SrFe}_{12-\mathrm{x}} \mathrm{Gd}_{\mathrm{x}} \mathrm{O}_{19} \mathrm{x}=0.0,0.1\right)$ have been synthesized by coprecipitation method. Structural analysis was done by using X-ray diffraction technique (XRD). It was found that the formation of single phase i.e. hexagonal structure has been achieved when the samples were sintered at $920^{\circ} \mathrm{C}$ for 20 minutes. AC electrical properties such as conductivity $\left(\sigma_{\text {ac }}\right)$, dielectric constant $\left(\varepsilon^{\prime}\right)$, dielectric loss $(\tan \delta)$ and impedance $(Z)$; real $\left(Z^{\prime}\right)$ and imaginary $\left(Z^{\prime \prime}\right)$ parts have been studied as a function of frequency at room temperature. Aim of the work was to enhance the resistivity and was successfully achieved. Gd doped sample is proposed as an energy efficient material to be used in devices working at high frequencies.
\end{abstract}

\section{Introduction}

As a metal oxide, Ferrites are believed to be the widest applied materials. Ferrites have two main types, Soft magnetic and hard magnetic ferrite. Soft ferrites are prepared by basic materials which are iron oxide and other metal oxides like manganese oxide, nickel oxide and zinc oxide [1]. Hard ferrites are widely used as permanent magnetic materials which are fabricated using strontium, barium and lead $[2,3]$. Among various advanced magnetic nano materials, M-type hexaferrite with chemical formula of $\mathrm{MeFe}_{12} \mathrm{O}_{19}(\mathrm{Me}=\mathrm{Sr}, \mathrm{Ba}$ and $\mathrm{Pb})$ had demonstrated to be an important class of magnetic materials. For vast scientific and technological interests these ferrites have emerged as multifunctional materials due to the stability of their properties [4]. In 1950's, a classical hard magnetic material, strontium ferrite $\left(\mathrm{SrFe}_{12} \mathrm{O}_{19}\right)$ was discovered. Which has high chemical stability, high coercivity, moderate remanence, high electrical resistivity and high magneto crystalline anisotropy compared with other magnetic materials [5]. Hexagonal ferrites have electrical and magnetic properties which are dependent on the condition in which synthesis take place and the site occupation of substitute cation with different $\mathrm{Fe}^{3+}$ sub-lattices named as trigonal bipyramid(2b), tetrahedral $(4 \mathrm{f})$ and octahedral $(12 \mathrm{k}, 2 \mathrm{a}$ and $4 \mathrm{f} 2)$ of hexagonal structure [6]. To enhance the properties of Sr-hexaferrite and making the material useful for different applications, various researcher doped different metal and combination of various metal cation.

Strontium hexaferrite ( $\mathrm{SrM}$ ) nanoparticles are prepared using various method such as sol-gel method [7], high temperature solid state reaction, hydrothermal method [8] and co-precipitation method for improving crystal lattice size, magnetic properties and morphology. In contrast to others, a co-precipitation method has raised deep attention on vast industrial production, low cost and allows to control the particle size more efficiently [9]. Gd rare earth metal is used as a dopant due to its comparable ionic radii to iron. In this work an attempt is made to enhance the resistivity of Sr-hexaferrite $\left(\mathrm{SrFe}_{12} \mathrm{O}_{19}\right)$ by using rare earth metal gadolinium as a dopant at iron site $\left(\mathrm{SrFe}_{12}\right.$ $\left.{ }_{\mathrm{x}} \mathrm{Gd}_{\mathrm{x}} \mathrm{O}_{19}, \mathrm{x}=0.0,0.1\right)$. As high resistance minimizes the eddy current losses [10]. 


\section{Experimental Techniques}

The chemical used in the synthesis of sample were $\mathrm{Sr}\left(\mathrm{NO}_{3}\right)_{2}, \mathrm{Fe}\left(\mathrm{NO}_{3}\right)_{3} \cdot 9 \mathrm{H}_{2} \mathrm{O}, \mathrm{GdN}_{3} \mathrm{O}_{9} \cdot 6 \mathrm{H}_{2} \mathrm{O}$. The Sr-hexaferrite samples substituted with Gd and having nominal composition $\operatorname{SrFe}_{12-\mathrm{x}} \mathrm{Gd}_{\mathrm{x}} \mathrm{O}_{19}(\mathrm{x}$ $=0.0,0.1)$ were prepared by chemical co-precipitation method. The details of this method have already been reported elsewhere [11]. The precursors were prepared by dissolving $\operatorname{Sr}\left(\mathrm{NO}_{3}\right)_{2}$, $\mathrm{Fe}\left(\mathrm{NO}_{3}\right)_{3} \cdot 9 \mathrm{H}_{2} \mathrm{O}$ and $\mathrm{GdN}_{3} \mathrm{O}_{9} \cdot 6 \mathrm{H}_{2} \mathrm{O}$ in deionized water. Stir the solutions separately for 15 minutes. Mix the precursor and heat it at $70^{\circ} \mathrm{C}$. To get $\mathrm{pH}$ of the solution equal to 12 , sodium hydroxide solution prepared by dissolving in $500 \mathrm{ml}$ deionized water was added in to the above solution. The mixture of all was kept for constant magnetic stirring at $70^{\circ} \mathrm{C}$ for 45 minutes. Brown precipitates were obtained after heating and to remove the by-products, the precipitates were washed by deionized water for 6,7 times respectively. The precipitates were dried in an oven at $105^{\circ} \mathrm{C}$.

\section{Results and Discussion}

Structural Analysis. XRD patterns of $\mathrm{SrFe}_{12-\mathrm{x}} \mathrm{Gd}_{\mathrm{x}} \mathrm{O}_{19}(\mathrm{x}=0.0,0.1)$ of as-prepared, calcined and sintered sample are shown in the Fig. 1 and Fig. 2. To investigate the structural properties of the samples X-ray diffraction technique was used. The source used for X-ray was $\mathrm{Cu}-\mathrm{K} \alpha$ having a wavelength of $1.54 \AA$. Crystallite size, crystal structure and lattice constant were calculated with the help of XRD data. Samples showed hexagonal structure. Scherer's formula was used to calculate the crystallite size.

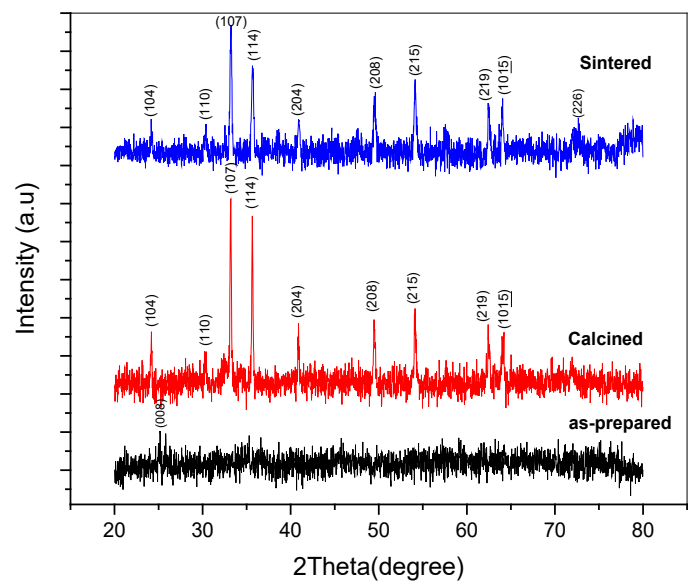

Fig. 1. XRD patterns of $\mathrm{SrFe}_{12} \mathrm{O}_{19}(\mathrm{x}=0.0)$

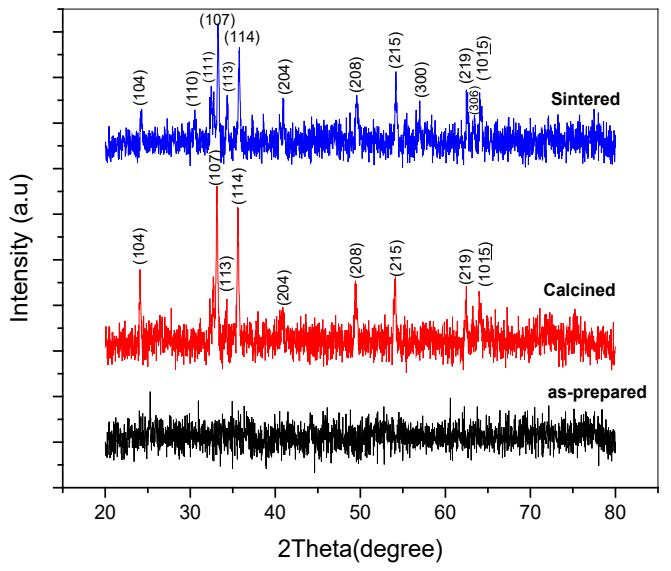

Fig. 2. XRD patterns of $\mathrm{SrFe}_{11.9} \mathrm{Gd}_{0.1} \mathrm{O}_{19}(\mathrm{x}=0.1)$

For as-prepared samples tetragonal structure while for heat treated samples hexagonal structure was observed having the space group of $\mathrm{P} 63 / \mathrm{mmc}$. This is in agreement to the already reported literature for the undoped sample [9]. The maximum intensity peak was observed at $2 \theta=33^{\circ}$ with (107) orientation. Average crystallite size lies between 34-37 nm. In XRD graphs of samples no impurity peak was observed which shows the successful synthesis of samples. The average crystallite size, lattice parameters and volume of unit cell of as-prepared, calcined and sintered sample are shown in Table 1.

Table 1. Crystallite sizes (Davg.), lattice constants and volume of unit cell of as-prepared, calcined and sintered $\left(\mathrm{SrFe}_{12-\mathrm{x}} \mathrm{Gd}_{\mathrm{x}} \mathrm{O}_{19}, \mathrm{x}=0.0,0.1\right)$ samples

\begin{tabular}{l|c|c|c|c|c|c}
\hline \multicolumn{1}{c}{ Parameters } & \multicolumn{2}{c|}{ As-prepared } & \multicolumn{2}{c}{ Calcined } & \multicolumn{2}{c}{ Sintered } \\
\hline $\begin{array}{l}\text { Average } \\
\text { crystallite size } \\
(\mathrm{nm})\end{array}$ & $\mathbf{x = 0 . 0}$ & $\mathbf{x = 0 . 1}$ & $\mathbf{x}=\mathbf{0 . 0}$ & $\mathbf{x}=\mathbf{0 . 1}$ & $\mathbf{x = 0 . 0}$ & $\mathbf{x = 0 . 1}$ \\
\cline { 2 - 7 } & 23 & $\begin{array}{l}\text { No peaks } \\
\text { observed }\end{array}$ & 54 & 38 & 37 & 37 \\
\hline $\mathrm{a}=\mathrm{b}(\AA)$ & 3.8860 & -- & $5.58(5)$ & $5.59(6)$ & $5.55(2)$ & $5.53(3)$ \\
\hline $\mathrm{c}(\AA)$ & 28.000 & --- & $22.74(2)$ & $23.73(3)$ & $22.96(2)$ & $23.119(4)$ \\
\hline $\mathrm{V}(\AA)^{3}$ & 422.83 & --- & $614.54(6)$ & $615.67(1)$ & $614.03(4)$ & $613.85(4)$ \\
\hline
\end{tabular}




\section{Electrical Analysis}

Dielectric properties such as ac conductivity, dielectric constant, dielectric loss and impedance of the samples were analyzed at different frequencies $(20 \mathrm{~Hz}-3 \mathrm{MHz})$.

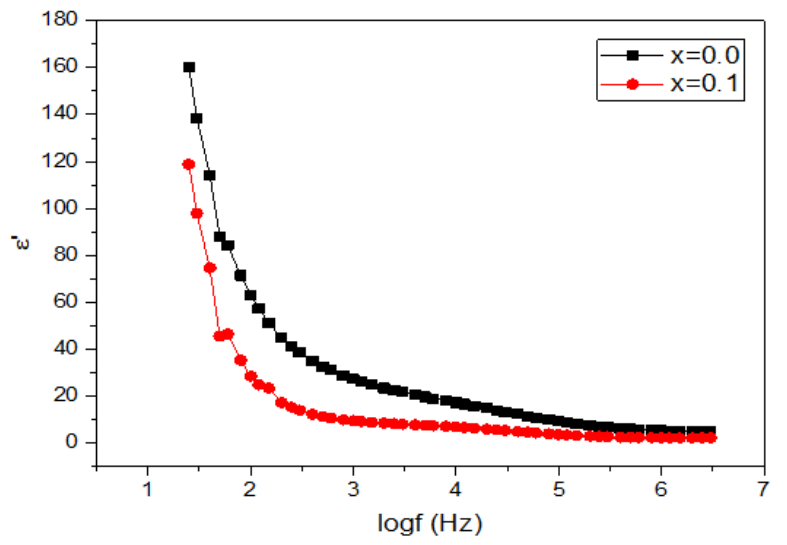

Fig. 3. Plots of $\dot{\varepsilon}$ vs $\log$ f of $\mathrm{SrFe}_{12-\mathrm{x}} \mathrm{Gd}_{\mathrm{x}} \mathrm{O}_{19}$

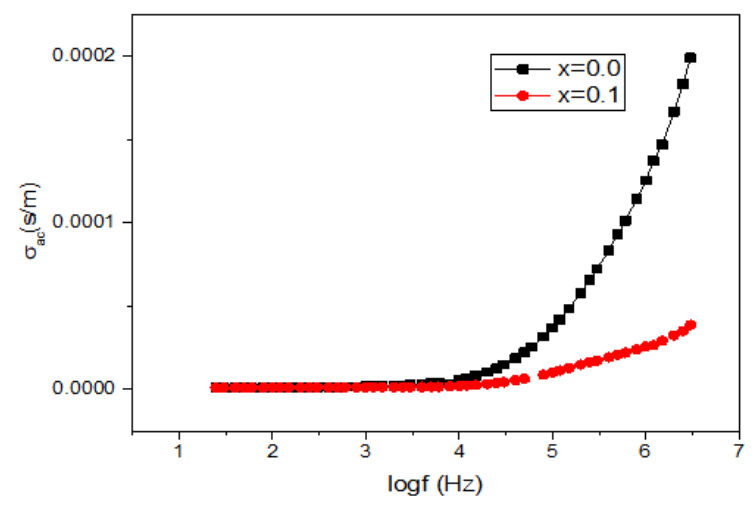

Fig. 5. Plots of $\sigma_{a c} v s \log f$ of $\operatorname{SrFe}_{12-x} G d_{x} O_{19}$

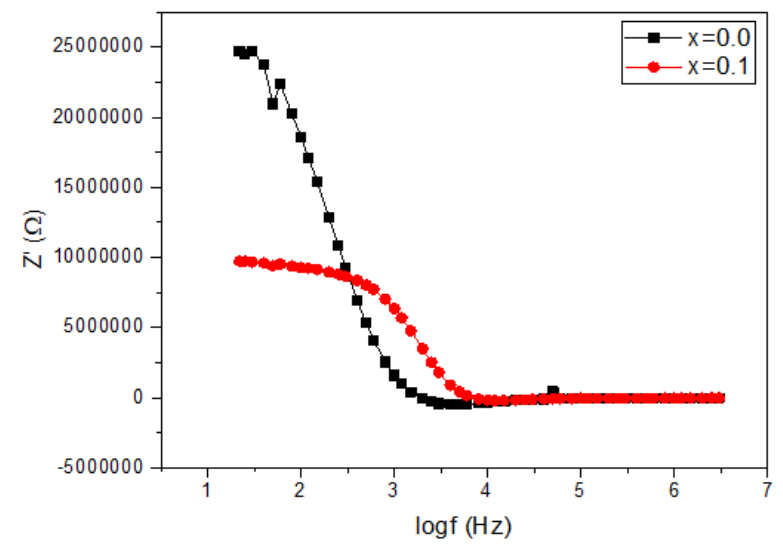

Fig. 7. Plots of Z' vs $\log$ f of $\mathrm{SrFe}_{12-\mathrm{x}} \mathrm{Gd}_{\mathrm{x}} \mathrm{O}_{19}$

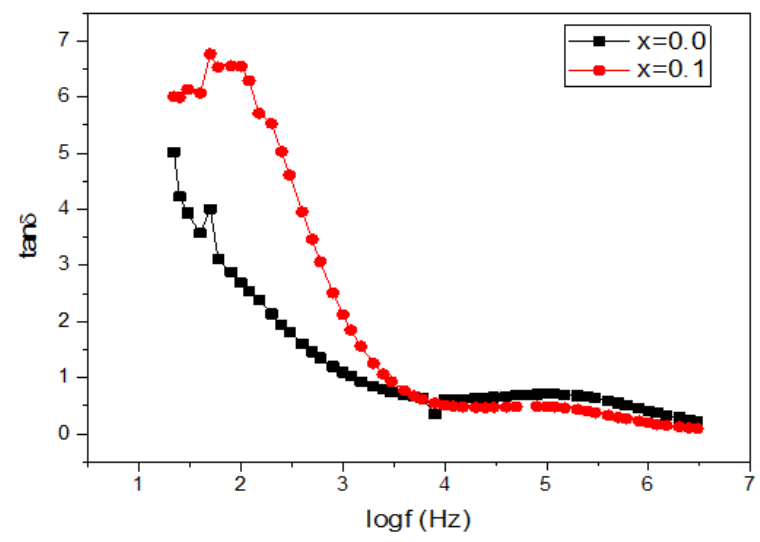

Fig. 4. Plots of $\tan \delta$ vs $\log$ f of $\mathrm{SrFe}_{12-\mathrm{x}} \mathrm{Gd}_{\mathrm{x}} \mathrm{O}_{19}$

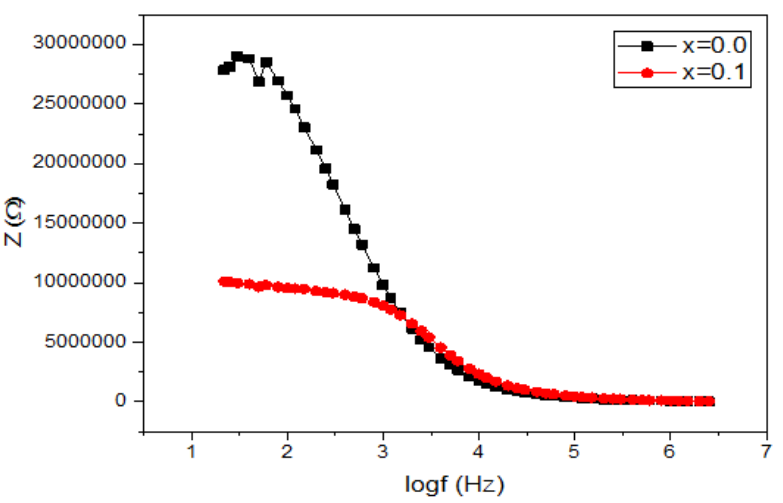

Fig. 6. Plots of $\mathrm{Z}$ vs $\log$ f of $\mathrm{SrFe}_{12-\mathrm{x}} \mathrm{Gd}_{\mathrm{x}} \mathrm{O}_{19}$

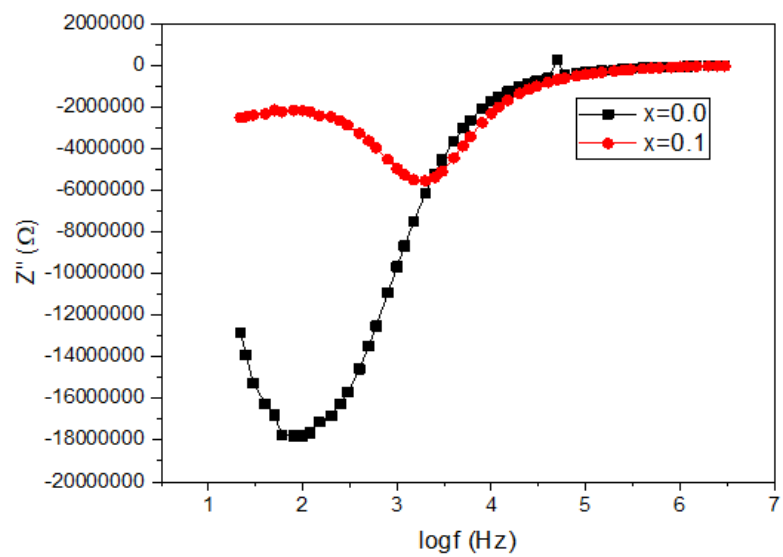

Fig. 8. Plots of Z', vs $\log$ f of $\mathrm{SrFe}_{12-\mathrm{x}} \mathrm{Gd}_{\mathrm{x}} \mathrm{O}_{19}$

Dielectric Constant. The dielectric constant $\left(\mathcal{E}^{\prime}\right)$ of pelletized samples is calculated using Eq.1:

$$
\varepsilon^{\prime}=\frac{C d}{\varepsilon_{\mathrm{o}} A}
$$

Where $\mathcal{E}^{\prime}$ is the dielectric constant, $C$ is the capacitance of sample, $\varepsilon_{\circ}$ is a constant known as the permittivity of free space having value of $8.854 \times 10^{-12} \mathrm{~F} / \mathrm{m}, \mathrm{d}$ is thickness and $A$ is area of the pellet respectively. Fig. 3 shows the behavior of dielectric constant at room temperature. Based on Maxwel-Wagner two-layer model behavior of dielectric can be explained. At lower frequency dielectric constant showed higher values which clearly indicate that all types of polarization are 
present here. By increasing applied frequency, the dielectric constant decreased sharply which indicate that polarization is going to decrease. Magnitude is comparable then that to the already reported in the literature [12]. Interface polarization vanished out at higher frequency region which result in decrease of dielectric constant. In ferrites, the polarization is directly depending upon $\mathrm{Fe}^{+2}$ ions concentration at a grain. The reason of decrease in dielectric constant with doping gadolinium is that the number of iron ions decreased when gadolinium dopant replaces iron ions from octahedral sites which results in decrease of hopping of electrons [13].

Dielectric Loss. Fig. 4 shows dielectric loss as a function of frequency. Similar to dielectric constant the dielectric loss dispersions occur at lower frequency region. By increasing frequency, the ions are unable to follow the applied frequency due to which dielectric loss almost remain same at higher frequency region. The dielectric loss also decreased by doping gadolinium at iron sites which result in decrease of $\mathrm{Fe}^{+2}$ concentrations which are the main reason of conduction losses.

Ac Conductivity. AC Conductivity $\left(\sigma_{\mathrm{ac}}\right)$ can be determine using Eq. 2:

$$
\sigma_{a c}=\omega \varepsilon_{\mathrm{o}} \varepsilon^{\prime} \tan \delta
$$

Here $\omega$ represent the angular frequency $\omega=2 \pi f, \varepsilon_{\circ}$ is permittivity of free space, $\varepsilon^{\prime}$ is dielectric constant and $\tan \delta$ is dielectric loss factor.

Fig. 5 showed AC Conductivity $\left(\sigma_{a c}\right)$ of $\operatorname{SrFe}_{12-\mathrm{x}} \mathrm{Gd}_{\mathrm{x}} \mathrm{O}_{19}(\mathrm{x}=0.0,0.1)$ as a function of frequency ranges from $20 \mathrm{~Hz}$ to $3 \mathrm{MHz}$ at room temperature. The trend of the graphs can be explained using jump relaxation model and similar behavior is reported for undoped sample [14].

$\mathrm{AC}$ conductivity increased by increasing frequency. At the beginning (low frequency region) the ac conductivity is almost constant. The conductivity at lower frequency region is due to the successful hopping of ions from one site to another available site. There is rapid increase in conductivity at higher frequency region which is called dispersion region. At dispersion region, not only the rate of successful hopping increased but also ions relax and reorient potential across it, due to which conductivity increased by applying frequency.

The composition $\mathrm{SrFe}_{12-\mathrm{x}} \mathrm{Gd}_{\mathrm{x}} \mathrm{O}_{19}(\mathrm{x}=0.0,0.1)$ clearly shows that gadolinium replaces iron. By doping gadolinium on iron site results in decrease of $\mathrm{Fe}^{+2}$ ions concentrations which are the main cause of hopping in ferrites. Pure Strontium hexaferrite $\mathrm{SrFe}_{12} \mathrm{O}_{19}$ (when $\mathrm{x}=0.0$ ) showed higher conductivity and conductivity decreased by doping gadolinium. By increasing concentration of dopant, the conductivity clearly decreased which indicate the successful doping and replacement of gadolinium on iron sites.

Impedance. Spectra of impedance at room temperature are shown in Figs. 6, 7 and 8 in the frequency range of $20 \mathrm{~Hz}$ to $3 \mathrm{MHz}$. Impedance decreased by increasing frequency. This indicates an increase in ac conductivity. Impedance behaved monotonically at lower frequencies and became independent of frequency at higher frequencies. The composition with $\mathrm{x}=0.1$ has shown greater impedance than that of $x=0.0$, at higher frequency.

\section{Conclusions}

Gd doped Strontium hexaferrite with composition $\mathrm{SrFe}_{12-\mathrm{x}} \mathrm{Gd}_{\mathrm{x}} \mathrm{O}_{19}(\mathrm{x}=0.0,0.1)$ powder was synthesized by co-precipitation method. XRD analysis assures the single phase hexagonal structure. The crystallite size of the synthesized sample ranges between 34 to $37 \mathrm{~nm}$. In the frequency range of $20 \mathrm{~Hz}-3 \mathrm{MHz}$, both dielectric constant and dielectric losses were measured. With the increase in doping concentration dielectric constants, dielectric losses were decreased due to decrease in $\mathrm{Fe}^{2+}$ ion concentration.

At higher frequencies ac conductivity increases sharply due to increasing hopping rate, relaxation and re orientation of ions. With the increase in doping concentration ac conductivity decreased which clearly indicate that resistivity improved by doping gadolinium. The results showed that by doping gadolinium in strontium hexaferrite resistivity improved and we can use gadolinium doped strontium hexaferrite in electrical devices to prevent energy losses. 


\section{Acknowledgement}

Higher Education Commission (HEC) is acknowledged for providing the financial support during this research.

\section{References}

[1] Q. Wu, Z. Yu, H. Hao, Y. Chu, H. Xie, The effect of $\mathrm{pH}$ value on strontium hexaferrites: microstructure and magnetic properties, J. Mater. Sci., 28 (2017) 12768-1277.

[2] I.H. Gul, F. Amin, AZ. Abbasi, M. Anis-ur-Rehman, A. Maqsood, Physical and magnetic characterization of co-precipitated nanosize Co-Ni ferrites, Scr. Mater., 56 (2007) 497-500.

[3] A. Hajalilou, S.A. Mazlan, A review on preparation techniques for synthesis of nanocrystalline soft magnetic ferrites and investigation on the effects of microstructure features on magnetic properties, J. Appl. Phys., 122 (2016) 1-15.

[4] P. Jing, J. Du, J. Wang, J. wei, L Pan, J. Li, Q. Liu, Width-controlled M-type hexagonal strontium ferrite $\left(\mathrm{SrFe}_{12} \mathrm{O}_{19}\right)$ nanoribbons with high saturation magnetization and superior coercivity synthesized by electrospinning, Sci. Rep., 5 (2015) 15089.

[5] A. Awadallah, S.H. Mahmood, Y. Maswadeh, I. Bsoul, A. Aloqaily, Structural and magnetic properties of vanadium doped M-type barium hexaferrite $\left(\mathrm{BaFe}_{12-\mathrm{x}} \mathrm{V}_{\mathrm{x}} \mathrm{O}_{19}\right)$, IOP., 92 (2015) 012006.

[6] M. J. Iqbal, M. N. Ashiq, P Hernandez-Gomez, J. M. Munoz, Synthesis, physical, magnetic and electric properties of Al-Ga substituted co-precipitated nanocrystalline strontium hexaferrite, J. Magn. Magn. Mater., 320 (2008) 881-886.

[7] W. Zhong, W. Ding, N. Zhang, J. Hong, Q. Yan, Y. Du, Key step in synthesis of ultrafine BaFe12O19 by sol-gel technique, J. Mater. Sci., 168 (1997) 196-202.

[8] J. F. Wang, C.B. Ponton, I.R. Harris, A study of La-substituted strontium hexaferrite by hydrothermal synthesis, J. Alloy. Compd., 369 (2004) 170-177.

[9] M. J. Iqbal, M. N. Ashiq, Physical and electrical properties of $\mathrm{Zr}-\mathrm{Cu}$ substituted strontium hexaferrite nanoparticles synthesized by co-precipitation method, Chem. Eng. J., 136 (2008) 383389.

[10] J. Gaudet, E. Schamiloglu, J.O. Rossi, C.J. Buchenauer, C. Frost, Nonlinear transmission lines for high power microwave applications - A Survey, IEEE. 334. (2013) 1-5.

[11] M. Anis-ur-Rehman, Z. Khan, S. Kanwal, Fatima-tuz-Zahra, Co-precipitated magneto plumbite nanoparticles and their structural and dielectric properties, IEEE. (2015)

[12] G. Asghar, M. Anis-ur-Rehman, Structural, dielectric and magnetic properties of Cr-Zn doped strontium hexa-ferrites for high frequency applications, J. Alloy. Compd., 526 (2012) 85-90.

[13] M. N. Ashiq, M. J. Iqbal, I. H. Gul, Effect of Al-Cr doping on the structural, magnetic and dielectric properties of strontium hexaferrite nanomaterials, J. Magn. Magn. Mater., 323 (2011) 259-263.

[14] M. Anis-ur-Rehman, Fatima-tuz-Zahra, S. Kanwal, Z. Khan, A. Asif, A. N. Hussain, S. Zahid, Study of dielectric relaxation in co-precipitated $\mathrm{Sr}-\mathrm{Fe}(\mathrm{Cr})$ nanoferrites, J. Mater Sci; Mater Electron., 26 (2015) 6539-6545. 